\title{
In Vitro Assessment of Shiitake Mushroom (Lentinula edodes) Extract for Its Antigingivitis Activity
}

\section{Lena Ciric, ${ }^{1}$ Anna Tymon, ${ }^{1}$ Egija Zaura, ${ }^{2}$ Peter Lingström, ${ }^{3}$ Monica Stauder, ${ }^{4}$ Adele Papetti, ${ }^{5}$ Caterina Signoretto, ${ }^{6}$ Jonathan Pratten, ${ }^{1}$ Michael Wilson, ${ }^{1}$ and David Spratt ${ }^{1}$}

${ }^{1}$ Department of Microbial Diseases, UCL Eastman Dental Institute, 256 Gray's Inn Road, London WC1X 8LD, UK

${ }^{2}$ Department of Preventive Dentistry, Academic Centre for Dentistry Amsterdam (ACTA), Gustav Mahlerlaan 3004, 1081 LA Amsterdam, The Netherlands

${ }^{3}$ Department of Cariology, Institute of Odontology at Sahlgrenska Academy, University of Gothenburg, 40530 Götegborg, Sweden

${ }^{4}$ DIPTERIS, University of Genoa, Corso Europa 26, 16132 Genoa, Italy

${ }^{5}$ Department of Drug Sciences, University of Pavia, Viale Taramelli 12, 27100 Pavia, Italy

${ }^{6}$ Dipartimento di Patologia-Sezione di Microbiologia, Università di Verona, 37134 Verona, Italy

Correspondence should be addressed to Lena Ciric, 1.ciric@ucl.ac.uk

Received 14 June 2011; Accepted 12 July 2011

Academic Editor: Carla Pruzzo

Copyright ( $) 2011$ Lena Ciric et al. This is an open access article distributed under the Creative Commons Attribution License, which permits unrestricted use, distribution, and reproduction in any medium, provided the original work is properly cited.

\begin{abstract}
Gingivitis is a preventable disease characterised by inflammation of the gums due to the buildup of a microbial biofilm at the gingival margin. It is implicated as a precursor to periodontitis, a much more serious problem which includes associated bone loss. Unfortunately, due to poor oral hygiene among the general population, gingivitis is prevalent and results in high treatment costs. Consequently, the option of treating gingivitis using functional foods, which promote oral health, is an attractive one. Medicinal mushrooms, including shiitake, have long been known for their immune system boosting as well as antimicrobial effects; however, they have not been employed in the treatment of oral disease. In the current study, the effectiveness of shiitake mushroom extract was compared to that of the active component in the leading gingivitis mouthwash, containing chlorhexidine, in an artificial mouth model (constant depth film fermenter). The total bacterial numbers as well as numbers of eight key taxa in the oral community were investigated over time using multiplex qPCR. The results indicated that shiitake mushroom extract lowered the numbers of some pathogenic taxa without affecting the taxa associated with health, unlike chlorhexidine which has a limited effect on all taxa.
\end{abstract}

\section{Introduction}

Gingivitis is one of the most prevalent infectious diseases of humans, affecting most of the population at some point during their lives [1]. It is easily preventable by the removal of the plaque biofilm but often results in high treatment costs due to poor oral hygiene among the general population. Gingivitis has long been implicated as a potential precursor to periodontitis $[2,3]$ and is caused by the buildup of the plaque biofilm at the gingival margin. This in turn results in a shift in the resident microbiota as a consequence of environmental changes $[4,5]$. The prevalence of Actinomyces spp., Lactobacillus spp., Prevotella spp., and Fusobacterium nucleatum is known to increase during gingivitis at the expense of Streptococcus spp. [6-9]. This community shift causes inflammation of the gingiva as part of the immune response $[3,10,11]$. The disease can be prevented and alleviated by the removal of the plaque biofilm and by the use of oral hygiene products such as toothbrushes, toothpastes, and mouthwashes [12]. The constant depth film fermenter (CDFF) has been used previously to model the bacterial community shifts observed during gingivitis and has also been employed to assess the effects of oral hygiene products $[13,14]$.

Medicinal mushrooms, including Lentinula edodes or shiitake, have been used in Asia for centuries and have numerous health benefits. These range from their antioxidant properties, to lowering cholesterol and blood pressure, antitumor properties, and antibacterial and libido-enhancing properties [15-18]. The health benefits of shiitake mushrooms are thought to be so great that they have been 
incorporated into some foods in order to be delivered to the population, creating functional foods including pork patties, cereals, and cookies $[16,19,20]$. However, shiitake has not as yet been assessed for its oral health benefits.

In recent years, high-throughput culture-independent quantitative methods have revolutionised the investigation of bacterial community structure. These methods are now being employed in the study of microbial communities involved in both oral health and disease [21-23]. In the present study, a set of assays developed previously was used to monitor the bacterial community structure changes within an in vitro gingivitis model and to assess the effect of shiitake mushroom extract and chlorhexidine, the leading agent used in the treatment of gum disease [24], on these communities.

\section{Materials and Methods}

2.1. Saliva Collection. Healthy individuals with good oral hygiene were asked to expectorate into a sterile centrifuge tube up to a volume of $2 \mathrm{~mL}$. Saliva was collected from 20 individuals. The saliva samples were homogenised into pooled saliva, and glycerol was added to a final concentration of $10 \% \mathrm{v} / \mathrm{v}$. The pooled saliva was dispensed into $1 \mathrm{~mL}$ aliquots and stored at $-80^{\circ} \mathrm{C}$.

2.2. CDFF Gingivitis Model. In vitro biofilms, representative of plaque that forms at the gingival margin, were cultured using a CDFF. The environmental conditions within the CDFF were modified in order to mimic those found during gingivitis, as described previously [14]. Briefly, the CDFF was inoculated by $1 \mathrm{~mL}$ of pooled saliva sample added to $500 \mathrm{~mL}$ artificial saliva medium [25] over 8 hours. The biofilms were cultured at $36^{\circ} \mathrm{C}$ for one week. The CDFF was kept under microaerophilic conditions using a gas mixture $\left(2 \% \mathrm{O}_{2} ; 3 \%\right.$ $\mathrm{CO}_{2} ; 95 \% \mathrm{~N}$ at $200 \times 10^{5} \mathrm{~Pa}$ ) pumped into the chamber through a filtered inlet at a rate of $200 \mathrm{~cm}^{3} \mathrm{~min}^{-1}$. Artificial saliva medium and artificial gingival crevicular fluid [26] were pumped into the chamber throughout the experiment at a flow rate of 0.72 litres day ${ }^{-1}$ and 0.072 litres day ${ }^{-1}$, respectively.

No antimicrobials were pumped into the CDFF during the no treatment control (NTC) experiments. During the chlorhexidine (CHX) and mushroom extract (MUSH) experiments, $0.12 \%$ chlorhexidine and $2 \mathrm{x}$ low molecular weight shiitake mushroom extract were pumped into the CDFF from $80 \mathrm{~h}$ and every 12 hours thereafter to mimic the use of a mouthwash twice daily. Each pulse was pumped in at a rate of $2 \mathrm{~mL} \mathrm{~min}^{-1}$ for 5 minutes.

One pan, containing five disks, was removed aseptically every 24 hours. The biomass of two disks was collected as described previously [14] in duplicate. DNA extractions were then performed on the biomass collected.

2.3. Low Molecular Weight Shiitake Mushroom Extract Preparation. The $2 \mathrm{x}$ low molecular weight mushroom extract was prepared as described by Daglia et al. [27].

2.4. DNA Extraction Method. Total nucleic acids were extracted from all samples according to a previously described protocol [28] using a bead-beating phenol: chloroform: isoamyl alcohol $(25: 24: 1)$ extraction followed by a $30 \%$ PEG 6000 precipitation and $70 \%$ ethanol wash. This method was found to be the least biased towards the extraction of nucleic acids from Gram-negative organisms.

2.5. qPCR Method. Three triplex qPCR assays were designed to enumerate four organisms associated with gingivitis (Actinomyces naeslundii, Fusobacterium nucleatum, Lactobacillus casei, and Prevotella intermedia), three organisms associated with oral health (Streptococcus sanguinis, Neisseria subflava, and Veillonella dispar), one organism strongly implicated in dental caries (Streptococcus mutans), and all organisms as described previously [23]. The detection limits for each of the single taxa were 20 cells and the number rose to 600 cells for the universal assay.

2.6. Statistics. Data were normalised by transformation using $\log _{10}$. ANOVA analysis was used to test whether changes between the treatments were significant (significant $P \leq$ 0.005 ; and slightly significant $P<0.01$ ).

\section{Results}

3.1. Saliva Community. The microbial community present in the pooled saliva used as the inoculum for the CDFF was analysed using qPCR. The numbers of each of the taxa analysed are shown in Figure 1. The mean $(n=3)$ total number of organisms per millilitre of pooled saliva was found to be $1.01( \pm 0.41) \times 10^{9}$ (standard deviation is shown in brackets). The specific taxa being investigated made up $3.75 \times 10^{8}$ of the organisms or $37.24 \%$ of the total. Of these taxa, the most numerous were $V$. dispar (22.8\%), followed by N. subflava (12.1\%) and F. nucleatum (1.8\%), and the least is $L$. casei $(0.05 \%)$. Very low variation was observed between the three saliva samples which were profiled.

3.2. Gingivitis CDFF Plaque Biofilm Communities. The data regarding the numbers of individual taxa analysed and the total number of bacteria present over the course of the treatment experiments is shown in Table 1.

3.2.1. No Treatment Control (NTC). There was little change in total numbers of organisms present over time, the numbers increased from around $10^{7}$ at the start to around $10^{8}$ cells per disk up to 72 hours and remaining at this level throughout the experiment. Numbers of $L$. casei, P. intermedia, and A. naeslundii were very low throughout. Other taxa increased over time (mainly between the $72 \mathrm{~h}$ sampling point and the $96 \mathrm{~h}$ point) by $3 \log _{10}$, for example, F. nucleatum (from $0.007 \%$ to $5.399 \%$ ), V. dispar (from $0.072 \%$ to $13.093 \%$ ), and N. subflava (from $0.022 \%$ to $78.446 \%$ ). S. sanguinis increased by $0.5 \log _{10}(0.139 \%$ to $0.379 \%)$. S. mutans was not detected at any time points.

3.2.2. Chlorhexidine Treatment (CHX). As with the NTC exper-iment, the total numbers of organisms remained broadly steady over the experiment. Numbers of $L$. casei, and $P$. intermedia, and A. naeslundii were found in similar levels 


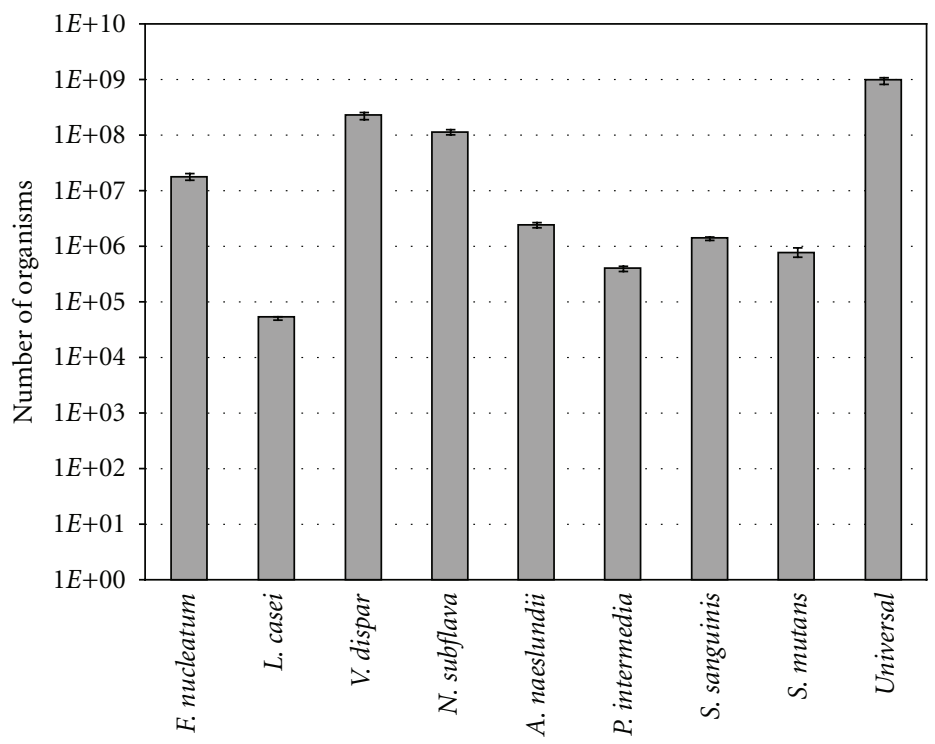

FIGURE 1: Numbers of each of the taxa investigated in pooled saliva. Error bars represent the standard deviation $(n=3)$.

as with the NTC experiment. However, numbers of N. subflava only rose by $1 \log _{10}$ throughout the experiment (from $3.838 \%$ to $10.919 \%$ ), number of $V$. dispar and S. sanguinis remained similar $(1.590 \%$ to $0.774 \% ; 0.360 \%$ to $0.275 \%$, resp.), and F. nucleatum deceased by around $1 \log _{10}$ (from $0.026 \%$ to $0.001 \%)$. S. mutans was not detected at any time points.

3.2.3. Mushroom Treatment (MUSH). Total numbers of organisms were found to be around $10^{8}$ cells per disk for the duration of the experiment. Numbers of L. casei, P. intermedia, and A. naeslundii were very low throughout. However, numbers of $N$. subflava rose by $3 \log _{10}$ (from $0.011 \%$ to $54.374 \%$ ) throughout the experiment, number of $V$. dispar rose by $6 \log _{10}(0.000002 \%$ to $8.556 \%)$ throughout the experiment, and F. nucleatum remained steady $(0.00001 \%$ to $0.00009 \%)$. S. sanguinis numbers rose by $2 \log _{10}(0.001 \%$ to $1.841 \%$ ) throughout the experiment. S. mutans was not detected at any time points.

3.3. Comparison of Taxa Numbers between Treatments. P. intermedia, $L$. casei, and A. naeslundii numbers were found in low numbers during all three of the treatments with no significant differences between treatments at any time points. The numbers of $N$. subflava cells appeared to be lower during the $\mathrm{CHX}$ treatment from $72 \mathrm{~h}$; however, no significant difference between treatments was found until the $168 \mathrm{~h}$ time point (NTC, $P=0.010$; MUSH, $P=0.004$ ) (Figure 2). $V$. dispar cell numbers were found to be significantly lower during the CHX treatment at $96 \mathrm{~h}, 120 \mathrm{~h}$, and $168 \mathrm{~h}(P \leq$ $0.003, P \leq 0.021$, and $P=0.001$, resp.) (Figure 2).

$S$. sanguinis numbers were significantly higher during the MUSH treatment than during the CHX treatment at time points $48,96,120$, and 168 hours $(P=0.047, P=0.052$, $P=0.032$, and $P=0.021$, resp.) (Figure 2). Numbers of $F$. nucleatum were found to be significantly lowered by the MUSH and CHX treatments from 96 hours onwards $(P \leq 0.030)$ (Figure 2). Finally, examining the universal assay cell numbers, the CHX experiment counts are significantly lower than those in the MUSH experiment at 48, 96, 120, and 168 hours $(P=0.010, P=0.019, P=0.044$, and $P=0.022$, resp.) (Figure 2).

\section{Discussion}

4.1. Saliva Community. The bacterial community found in salivary fluid is composed of the amalgamation of the communities found around the mouth. The predominant taxa were found to be $V$. dispar, $N$. subflava, F. nucleatum, A. naeslundii, and $S$. sanguinis. These taxa have all been associated with healthy dental plaque biofilms in previous culture independent studies $[29,30]$. The tongue community in healthy subjects has previously been found to comprise mostly Streptococcus spp., Veillonella spp., and Actinomyces spp. [31, 32]. A recent study looking into the unculturable microbiota of the tongue has also identified the above genera, along with a Lysobacter-type species as the predominant organism found on the tongue [33].

Two studies using culture-independent molecular methods have shown that the dominant phyla most commonly found in saliva were Firmicutes, Bacteriodetes, Proteobacteria, Actinobacteria, and Fusobacteria, respectively $[22,34]$. The multitriplex qPCR method showed a similar picture: the Firmicutes were the dominant organisms, followed by Proteobacteria, Fusobacteria, Actinobacteria, and Bacteriodetes.

4.2. CDFF Plaque Biofilm Communities. Whilst the universal assay confirmed total cells numbers in the biofilms to be high in all of the CDFF experiments, some of the taxa investigated were only detected in low levels including $P$. intermedia, $L$. casei, S. mutans, and A. naeslundii. While Actinomyces spp. are known to be one of the early colonizers in the formation 
TABLE 1: Numbers of each of the taxa investigated in biofilms grown in the gingivitis CDFF over one week under various treatments: Control $(n=2)$, Chlorhexidine $(n=4)$, and LMW mushroom $(n=2)$ pulsing.

\begin{tabular}{|c|c|c|c|c|c|c|c|}
\hline \multicolumn{8}{|l|}{ Control } \\
\hline & $24 \mathrm{~h}$ & $48 \mathrm{~h}$ & $72 \mathrm{~h}$ & $96 \mathrm{~h}$ & $120 \mathrm{~h}$ & $144 \mathrm{~h}$ & $168 \mathrm{~h}$ \\
\hline F. nucleatum & $\begin{array}{c}4.68( \pm 0.71) \\
\times 10^{3}\end{array}$ & $\begin{array}{c}1.38( \pm 0.11) \\
\times 10^{3}\end{array}$ & $\begin{array}{c}5.39( \pm 0.41) \\
\times 10^{3}\end{array}$ & $\begin{array}{c}5.07( \pm 0.05) \\
\times 10^{5}\end{array}$ & $\begin{array}{c}2.99( \pm 1.82) \\
\times 10^{6}\end{array}$ & $\begin{array}{c}3.31( \pm 0.87) \\
\times 10^{6}\end{array}$ & $\begin{array}{c}6.26( \pm 0.30) \\
\times 10^{6}\end{array}$ \\
\hline L. casei & $\begin{array}{c}6.20( \pm 4.81) \\
\times 10^{2}\end{array}$ & $\begin{array}{c}7.80( \pm 4.53) \\
\times 10^{2}\end{array}$ & $\begin{array}{c}7.80( \pm 4.53) \\
\times 10^{2}\end{array}$ & $\begin{array}{c}8.20( \pm 9.05) \\
\times 10^{2}\end{array}$ & $\begin{array}{c}9.10( \pm 9.76) \\
\times 10^{2}\end{array}$ & $\begin{array}{c}9.80( \pm 9.33) \\
\times 10^{2}\end{array}$ & $\begin{array}{c}9.00( \pm 10.7) \\
\times 10^{2}\end{array}$ \\
\hline V. dispar & $\begin{array}{c}4.91( \pm 4.13) \\
\times 10^{4}\end{array}$ & $\begin{array}{c}2.29( \pm 2.18) \\
\times 10^{5}\end{array}$ & $\begin{array}{c}2.65( \pm 1.41) \\
\times 10^{6}\end{array}$ & $\begin{array}{c}7.83( \pm 3.74) \\
\times 10^{6}\end{array}$ & $\begin{array}{c}8.94( \pm 7.24) \\
\times 10^{6}\end{array}$ & $\begin{array}{c}8.28( \pm 3.96) \\
\times 10^{6}\end{array}$ & $\begin{array}{c}1.52( \pm 0.26) \\
\times 10^{7}\end{array}$ \\
\hline N. subflava & $\begin{array}{c}1.52( \pm 0.72) \\
\times 10^{4}\end{array}$ & $\begin{array}{c}2.43( \pm 1.80) \\
\times 10^{5}\end{array}$ & $\begin{array}{c}2.49( \pm 1.70) \\
\times 10^{7}\end{array}$ & $\begin{array}{c}3.69( \pm 1.79) \\
\times 10^{7}\end{array}$ & $\begin{aligned} & 6.49( \pm 5.97) \\
& \times 10^{7}\end{aligned}$ & $\begin{array}{c}5.51( \pm 4.14) \\
\times 10^{7}\end{array}$ & $\begin{array}{c}9.10( \pm 3.74) \\
\times 10^{7}\end{array}$ \\
\hline A. naeslundii & $\begin{array}{c}6.00( \pm 8.49) \\
\times 10^{1}\end{array}$ & $\begin{array}{c}4.00( \pm 5.66) \\
\times 10^{1}\end{array}$ & $\begin{array}{c}1.00( \pm 1.41) \\
\times 10^{1}\end{array}$ & $\begin{array}{c}2.80( \pm 1.70) \\
\times 10^{2}\end{array}$ & $\begin{array}{c}1.60( \pm 0.28) \\
\times 10^{2}\end{array}$ & $\begin{array}{c}1.40( \pm 0.57) \\
\times 10^{2}\end{array}$ & $\begin{array}{c}2.40( \pm 3.11) \\
\times 10^{2}\end{array}$ \\
\hline P. intermedia & $\begin{array}{c}5.00( \pm 1.41) \\
\times 10^{1}\end{array}$ & $\begin{array}{c}5.00( \pm 1.41) \\
\times 10^{1}\end{array}$ & $\begin{array}{c}6.00( \pm 0.00) \\
\times 10^{1}\end{array}$ & $\begin{array}{c}4.00( \pm 2.83) \\
\times 10^{1}\end{array}$ & $\begin{array}{c}4.00( \pm 2.83) \\
\times 10^{1}\end{array}$ & $\begin{array}{c}3.00( \pm 1.41) \\
\times 10^{1}\end{array}$ & $\begin{array}{c}5.00( \pm 1.41) \\
\times 10^{1}\end{array}$ \\
\hline S. sanguinis & $\begin{array}{c}9.49( \pm 1.65) \\
\times 10^{4}\end{array}$ & $\begin{array}{c}8.05( \pm 1.41) \\
\times 10^{4}\end{array}$ & $\begin{array}{c}1.39( \pm 0.59) \\
\times 10^{6}\end{array}$ & $\begin{array}{c}5.63( \pm 0.99) \\
\times 10^{5}\end{array}$ & $\begin{array}{c}3.15( \pm 1.63) \\
\times 10^{5}\end{array}$ & $\begin{array}{c}5.18( \pm 3.05) \\
\times 10^{5}\end{array}$ & $\begin{array}{c}4.40( \pm 1.71) \\
\times 10^{5}\end{array}$ \\
\hline Universal & $\begin{array}{c}6.81( \pm 2.59) \\
\times 10^{7}\end{array}$ & $\begin{array}{c}3.48( \pm 2.22) \\
\times 10^{7}\end{array}$ & $\begin{array}{c}1.56( \pm 1.02) \\
\times 10^{8}\end{array}$ & $\begin{array}{c}1.72( \pm 1.08) \\
\times 10^{8}\end{array}$ & $\begin{array}{c}1.51( \pm 1.28) \\
\times 10^{8}\end{array}$ & $\begin{array}{c}1.30( \pm 0.83) \\
\times 10^{8}\end{array}$ & $\begin{array}{c}1.61( \pm 0.01) \\
\times 10^{8}\end{array}$ \\
\hline \multicolumn{8}{|l|}{ Chlorhexidine } \\
\hline & $24 \mathrm{~h}$ & $48 \mathrm{~h}$ & $72 \mathrm{~h}$ & $96 \mathrm{~h}$ & $120 \mathrm{~h}$ & $144 \mathrm{~h}$ & $168 \mathrm{~h}$ \\
\hline F. nucleatum & $\begin{array}{c}5.28( \pm 8.28) \\
\times 10^{3}\end{array}$ & $\begin{array}{c}8.25( \pm 9.77) \\
\times 10^{2}\end{array}$ & $\begin{array}{c}2.05( \pm 4.10) \\
\times 10^{2}\end{array}$ & $\begin{array}{c}6.40( \pm 7.18) \\
\times 10^{2}\end{array}$ & $\begin{array}{c}6.00( \pm 6.37) \\
\times 10^{2}\end{array}$ & $\begin{array}{c}2.80( \pm 5.20) \\
\times 10^{2}\end{array}$ & $\begin{array}{c}5.05( \pm 4.71) \\
\times 10^{2}\end{array}$ \\
\hline L. casei & $\begin{array}{c}3.60( \pm 5.80) \\
\times 10^{2}\end{array}$ & $\begin{array}{c}2.60( \pm 3.81) \\
\times 10^{2}\end{array}$ & $\begin{array}{c}6.50( \pm 13.0) \\
\times 10^{1}\end{array}$ & $\begin{array}{c}3.20( \pm 5.13) \\
\times 10^{2}\end{array}$ & $\begin{array}{c}2.60( \pm 3.59) \\
\times 10^{2}\end{array}$ & $\begin{array}{c}6.00( \pm 10.7) \\
\times 10^{1}\end{array}$ & $\begin{array}{c}3.15( \pm 3.00) \\
\times 10^{2}\end{array}$ \\
\hline V. dispar & $\begin{array}{c}3.28( \pm 5.02) \\
\times 10^{5}\end{array}$ & $\begin{array}{c}4.05( \pm 5.69) \\
\times 10^{5}\end{array}$ & $\begin{array}{c}3.53( \pm 3.35) \\
\times 10^{5}\end{array}$ & $\begin{array}{c}4.86( \pm 2.24) \\
\times 10^{5}\end{array}$ & $\begin{array}{c}2.08( \pm 1.93) \\
\times 10^{5}\end{array}$ & $\begin{array}{c}7.02( \pm 7.24) \\
\times 10^{5}\end{array}$ & $\begin{array}{c}5.65( \pm 2.77) \\
\times 10^{5}\end{array}$ \\
\hline N. subflava & $\begin{array}{c}7.91( \pm 10.0) \\
\times 10^{5}\end{array}$ & $\begin{array}{c}5.98( \pm 8.67) \\
\times 10^{5}\end{array}$ & $\begin{array}{c}4.80( \pm 4.91) \\
\times 10^{6}\end{array}$ & $\begin{array}{c}9.34( \pm 12.1) \\
\times 10^{6}\end{array}$ & $\begin{array}{c}6.95( \pm 7.91) \\
\times 10^{6}\end{array}$ & $\begin{array}{c}1.08( \pm 1.21) \\
\times 10^{7}\end{array}$ & $\begin{array}{c}7.97( \pm 4.94) \\
\times 10^{6}\end{array}$ \\
\hline A. naeslundii & $\begin{array}{c}3.88( \pm 3.47) \\
\times 10^{1}\end{array}$ & $\begin{array}{c}1.15( \pm 1.92) \\
\times 10^{1}\end{array}$ & $\begin{array}{c}0.00( \pm 0.00) \\
\times 10^{0}\end{array}$ & $\begin{array}{c}1.50( \pm 3.00) \\
\times 10^{1}\end{array}$ & $\begin{array}{c}1.00( \pm 2.00) \\
\times 10^{1}\end{array}$ & $\begin{array}{c}1.50( \pm 3.00) \\
\times 10^{1}\end{array}$ & $\begin{array}{c}9.75( \pm 12.1) \\
\times 10^{0}\end{array}$ \\
\hline P. intermedia & $\begin{array}{c}4.00( \pm 4.90) \\
\times 10^{1}\end{array}$ & $\begin{array}{c}4.00( \pm 4.32) \\
\times 10^{1}\end{array}$ & $\begin{array}{c}2.50( \pm 3.79) \\
\times 10^{1}\end{array}$ & $\begin{array}{c}5.50( \pm 5.26) \\
\times 10^{1}\end{array}$ & $\begin{array}{c}4.50( \pm 4.43) \\
\times 10^{1}\end{array}$ & $\begin{array}{c}2.00( \pm 2.83) \\
\times 10^{1}\end{array}$ & $\begin{array}{c}3.50( \pm 3.00) \\
\times 10^{1}\end{array}$ \\
\hline S. sanguinis & $\begin{array}{c}7.41( \pm 8.43) \\
\times 10^{4}\end{array}$ & $\begin{array}{c}2.25( \pm 2.39) \\
\times 10^{4}\end{array}$ & $\begin{array}{c}5.75( \pm 6.38) \\
\times 10^{4}\end{array}$ & $\begin{array}{c}1.39( \pm 1.52) \\
\times 10^{5}\end{array}$ & $\begin{array}{c}7.38( \pm 7.62) \\
\times 10^{4}\end{array}$ & $\begin{array}{c}9.35( \pm 10.3) \\
\times 10^{4}\end{array}$ & $\begin{array}{c}2.01( \pm 1.69) \\
\times 10^{5}\end{array}$ \\
\hline Universal & $\begin{array}{c}2.06( \pm 2.57) \\
\times 10^{7} \\
\end{array}$ & $\begin{array}{c}1.49( \pm 0.47) \\
\times 10^{7}\end{array}$ & $\begin{array}{c}2.99( \pm 2.57) \\
\times 10^{7}\end{array}$ & $\begin{array}{c}5.01( \pm 1.91) \\
\times 10^{7}\end{array}$ & $\begin{array}{c}4.33( \pm 2.17) \\
\times 10^{7} \\
\end{array}$ & $\begin{array}{c}6.75( \pm 4.92) \\
\times 10^{7}\end{array}$ & $\begin{array}{c}7.30( \pm 2.85) \\
\times 10^{7} \\
\end{array}$ \\
\hline \multicolumn{8}{|c|}{ LMW mushroom } \\
\hline & $24 \mathrm{~h}$ & $48 \mathrm{~h}$ & $72 \mathrm{~h}$ & $96 \mathrm{~h}$ & $120 \mathrm{~h}$ & $144 \mathrm{~h}$ & $168 \mathrm{~h}$ \\
\hline F. nucleatum & $\begin{array}{c}3.30( \pm 3.82) \\
\times 10^{2}\end{array}$ & $\begin{array}{c}5.40( \pm 2.26) \\
\times 10^{2}\end{array}$ & $\begin{array}{c}3.40( \pm 3.68) \\
\times 10^{2}\end{array}$ & $\begin{array}{c}3.10( \pm 2.12) \\
\times 10^{2}\end{array}$ & $\begin{array}{c}6.60( \pm 9.33) \\
\times 10^{2}\end{array}$ & $\begin{array}{c}3.40( \pm 3.96) \\
\times 10^{2}\end{array}$ & $\begin{array}{c}2.40( \pm 3.11) \\
\times 10^{2}\end{array}$ \\
\hline L. casei & $\begin{array}{c}1.05( \pm 1.34) \\
\times 10^{1}\end{array}$ & $\begin{array}{c}5.10( \pm 3.54) \\
\times 10^{2}\end{array}$ & $\begin{array}{c}1.90( \pm 1.27) \\
\times 10^{2}\end{array}$ & $\begin{array}{c}5.00( \pm 7.07) \\
\times 10^{1}\end{array}$ & $\begin{array}{c}5.00( \pm 7.07) \\
\times 10^{1}\end{array}$ & $\begin{array}{c}7.00( \pm 9.90) \\
\times 10^{1}\end{array}$ & $\begin{array}{c}5.00( \pm 7.07) \\
\times 10^{-1}\end{array}$ \\
\hline V. dispar & $\begin{array}{c}8.05( \pm 11.2) \\
\times 10^{1}\end{array}$ & $\begin{array}{c}1.32( \pm 0.29) \\
\times 10^{4}\end{array}$ & $\begin{array}{c}6.73( \pm 0.05) \\
\times 10^{6}\end{array}$ & $\begin{array}{c}6.92( \pm 2.18) \\
\times 10^{6}\end{array}$ & $\begin{array}{c}1.46( \pm 0.65) \\
\times 10^{7}\end{array}$ & $\begin{array}{c}2.43( \pm 1.19) \\
\times 10^{7}\end{array}$ & $\begin{array}{c}2.35( \pm 1.09) \\
\times 10^{7}\end{array}$ \\
\hline N. subflava & $\begin{array}{c}4.86( \pm 1.78) \\
\times 10^{5}\end{array}$ & $\begin{array}{c}2.20( \pm 1.40) \\
\times 10^{7}\end{array}$ & $\begin{array}{c}5.39( \pm 2.25) \\
\times 10^{7}\end{array}$ & $\begin{array}{c}7.10( \pm 3.29) \\
\times 10^{7}\end{array}$ & $\begin{array}{c}1.26( \pm 0.65) \\
\times 10^{8}\end{array}$ & $\begin{array}{c}1.40( \pm 0.83) \\
\times 10^{8}\end{array}$ & $\begin{array}{c}1.50( \pm 0.50) \\
\times 10^{8}\end{array}$ \\
\hline A. naeslundii & $\begin{array}{c}0.00( \pm 0.00) \\
\times 10^{0}\end{array}$ & $\begin{array}{c}2.00( \pm 2.83) \\
\times 10^{1}\end{array}$ & $\begin{array}{c}2.20( \pm 0.57) \\
\times 10^{2}\end{array}$ & $\begin{array}{c}3.00( \pm 1.41) \\
\times 10^{1}\end{array}$ & $\begin{array}{c}0.00( \pm 0.00) \\
\times 10^{0}\end{array}$ & $\begin{array}{c}0.00( \pm 0.00) \\
\times 10^{0}\end{array}$ & $\begin{array}{c}0.00( \pm 0.00) \\
\times 10^{0}\end{array}$ \\
\hline P. intermedia & $\begin{array}{c}1.00( \pm 1.41) \\
\times 10^{1}\end{array}$ & $\begin{array}{c}1.00( \pm 1.41) \\
\times 10^{1}\end{array}$ & $\begin{array}{c}1.00( \pm 1.41) \\
\times 10^{1}\end{array}$ & $\begin{array}{c}2.00( \pm 2.83) \\
\times 10^{1}\end{array}$ & $\begin{array}{c}3.00( \pm 4.24) \\
\times 10^{1}\end{array}$ & $\begin{array}{c}1.00( \pm 1.41) \\
\times 10^{1}\end{array}$ & $\begin{array}{c}2.00( \pm 2.83) \\
\times 10^{1}\end{array}$ \\
\hline S. sanguinis & $\begin{array}{c}5.99( \pm 4.29) \\
\times 10^{4}\end{array}$ & $\begin{array}{c}8.67( \pm 3.87) \\
\times 10^{5}\end{array}$ & $\begin{array}{c}3.72( \pm 0.76) \\
\times 10^{6}\end{array}$ & $\begin{array}{c}6.36( \pm 2.07) \\
\times 10^{6}\end{array}$ & $\begin{array}{c}6.55( \pm 1.97) \\
\times 10^{6}\end{array}$ & $\begin{array}{c}5.99( \pm 2.97) \\
\times 10^{6}\end{array}$ & $\begin{array}{c}5.06( \pm 1.58) \\
\times 10^{6}\end{array}$ \\
\hline Universal & $\begin{array}{c}4.60( \pm 2.56) \\
\times 10^{7}\end{array}$ & $\begin{array}{c}8.96( \pm 1.11) \\
\times 10^{7}\end{array}$ & $\begin{array}{c}1.98( \pm 0.69) \\
\times 10^{8}\end{array}$ & $\begin{array}{c}2.88( \pm 0.39) \\
\times 10^{8}\end{array}$ & $\begin{array}{c}3.80( \pm 1.04) \\
\times 10^{8}\end{array}$ & $\begin{array}{c}3.25( \pm 0.12) \\
\times 10^{8}\end{array}$ & $\begin{array}{c}2.75( \pm 0.59) \\
\times 10^{8}\end{array}$ \\
\hline
\end{tabular}



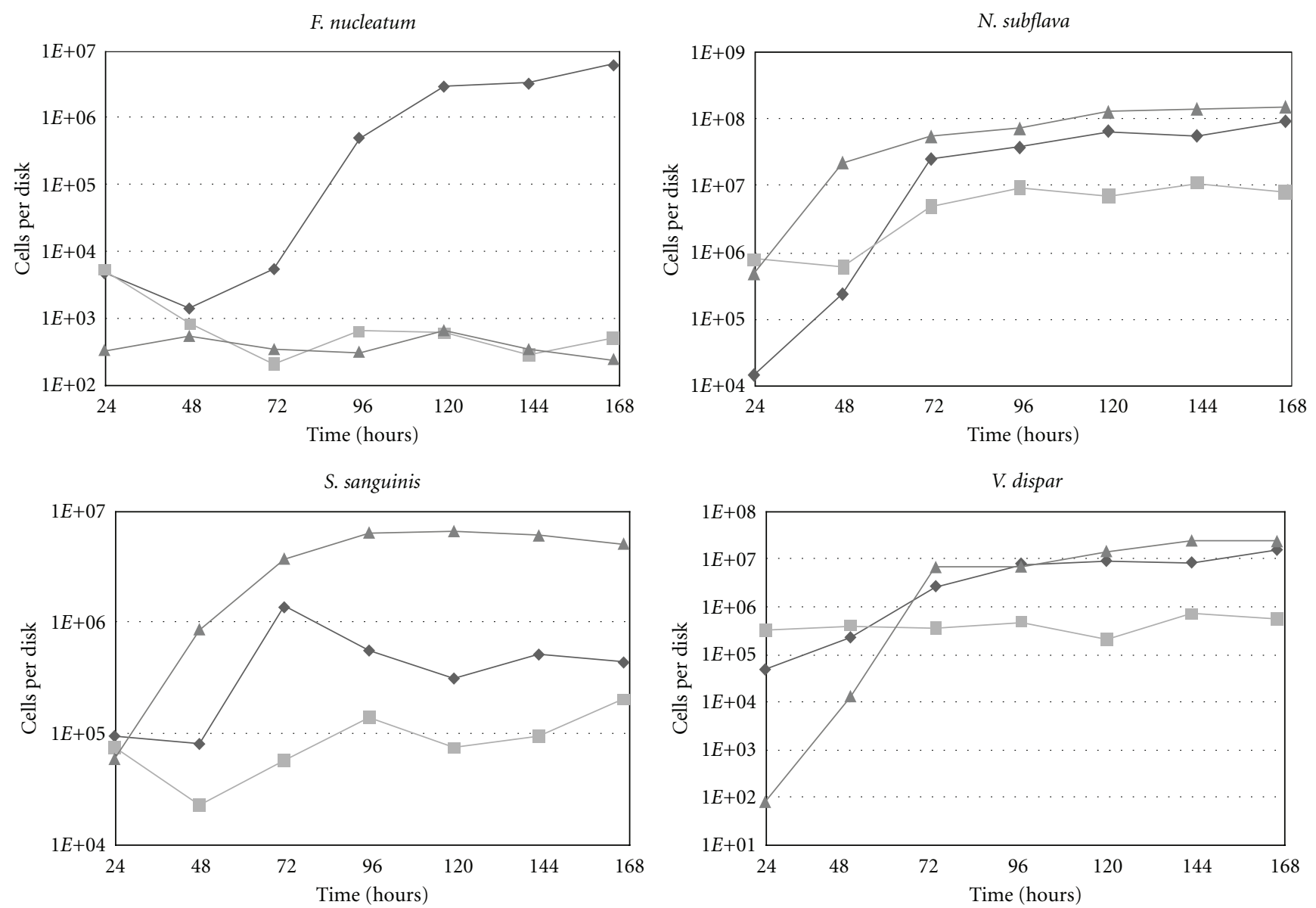

Universal

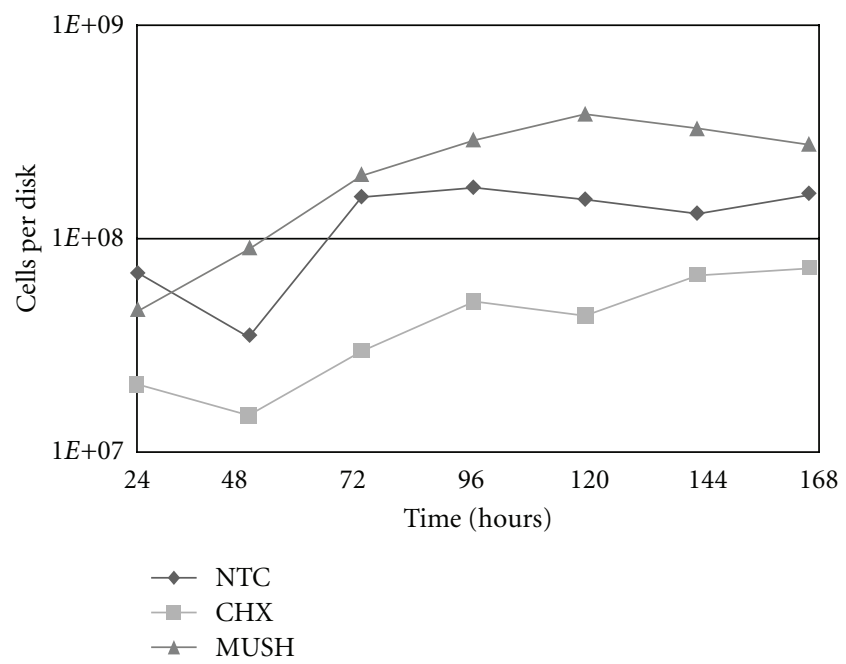

Figure 2: F. nucleatum, N. subflava, S. sanguinis, V. dispar, and total bacterial cell numbers which displayed significant differences between the different treatments.

of dental plaque [35], A. naeslundii is only one species representative of this genus. It is likely that the environmental conditions within the CDFF experiments were not optimal for the above taxon, but other members of the genus may have been present. Previous studies have found that $L$. case $i$, S. mutans, and A. naeslundii all grow well in biofilms cultured using saliva and the addition of a carbohydrate such as glucose or sucrose $[22,36]$. The lack of glucose or sucrose in the culture media in the present study could account for the low detection rates of these organisms. A previous study has shown that Prevotella spp. were detectable in the CDFF inoculum but not during the duration of the experiment 
using molecular methods [37], supporting the data from the current study where the pathogen was detected at very low levels throughout.

The organisms found in consistently high numbers from the beginning of all of the experiments were N. subflava, $S$. sanguinis, and $V$. dispar. All of these organisms have been shown to be early colonizers during the formation of dental plaque as well as being among the most abundant taxa in the oral cavity $[34,35,38]$. F. nucleatum numbers increased at a slightly later stage of plaque biofilm formation once the environmental conditions were optimal [39], as seen in the NTC experiment designed to mimic conditions during gingivitis.

Gingivitis is caused by the buildup of the plaque biofilm at the gingival margin, which in turn results in a shift in the resident microbiota as a consequence of environmental changes $[4,5]$. The prevalence of Actinomyces spp., Lactobacillus spp., Prevotella spp., and F. nucleatum is known to increase during gingivitis at the expense of Streptococcus spp. [6, 7, 9]. It was apparent that numbers of $F$. nucleatum rose over time in the NTC experiment and that $S$. sanguinis numbers declined after an initial peak at $72 \mathrm{~h}$ coinciding with the F. nucleatum increase.

Looking at the treatment effects, the application of chlorhexidine significantly lowered the numbers of $N$. subflava, $V$. dispar, and F. nucleatum compared to NTC The total cell numbers were also lower during the $\mathrm{CHX}$ treatment, no doubt in part due to the lower numbers of the above taxa. Chlorhexidine is considered the gold standard [24] in the treatment of gum disease, and its action has been well studied. Previous studies looking at the effects of chlorhexidine on plaque biofilms in vitro have shown an effect on Veillonella sp., Fusobacterium sp., and Streptococcus sp. numbers [22, 25], supported by the current study. The MUSH treatment significantly lowered the numbers of $F$. nucleatum, an oral pathogen, but also resulted in significantly higher numbers of $S$. sanguinis, normally associated with oral health, when compared to the CHX treatment. This increase in S. sanguinis numbers despite the gingivitis conditions in the CDFF is an important effect. Furthermore, the MUSH treatment did not have a negative effect on $N$. subflava and $V$. dispar, both organisms associated with oral health $[34,38]$. The data presented in the current study are supported by previous research which demonstrated the antimicrobial effects of shiitake mushroom products on a number of Gram-positive and negative organisms including some oral pathogens [17, $40,41]$.

In conclusion, the comparison of the different treatments using the CDFF has given a valuable insight into the community dynamics of dental plaque as well as an indication of the efficacy of the treatments. Chlorhexidine was found to be effective at lowering a number of taxa, associated with both health and disease; however, shiitake mushroom extract was shown to be effective at reducing the numbers of the oral pathogen F. nucleatum, while having little effect on some of the taxa associated with health. The results imply that the action of shiitake mushroom extract should be investigated further for its beneficial effects on oral health.

\section{Acknowledgment}

The research leading to these results has received funding from the European Union's Sixth Framework Programme (FP6) under the Contract no. FOOD-CT-2006-036210 (Project NUTRIDENT).

\section{References}

[1] J. M. Albandar, "Global risk factors and risk indicators for periodontal diseases," Periodontology 2000, vol. 29, no. 1, pp. 177-206, 2002.

[2] A. Tanner, M. F. J. Maiden, P. J. Macuch, L. L. Murray, and R. L. Kent, "Microbiota of health, gingivitis, and initial periodontitis," Journal of Clinical Periodontology, vol. 25, no. 2, pp. 85-98, 1998.

[3] P. D. Marsh, "Microbial ecology of dental plaque and its significance in health and disease," Advances in Dental Research, vol. 8, no. 2, pp. 263-271, 1994.

[4] J. M. Goodson, “Gingival crevice fluid flow," Periodontology 2000, vol. 31, pp. 43-54, 2003.

[5] W. J. Loesche, F. Gusberti, and G. Mettraux, "Relationship between oxygen tension and subgingival bacterial flora in untreated human periodontal pockets," Infection and Immunity, vol. 42, no. 2, pp. 659-667, 1983.

[6] W. E. Moore and L. V. Moore, "The bacteria of periodontal diseases," Periodontology 2000, vol. 5, pp. 66-77, 1994.

[7] W. E. C. Moore, L. V. Holdeman, and R. M. Smibert, "Bacteriology of experimental gingivitis in young adult humans," Infection and Immunity, vol. 38, no. 2, pp. 651-667, 1982.

[8] K. Y. Zee, L. P. Samaranayake, and R. Attstrom, "Predominant cultivable supragingival plaque in Chinese "rapid" and "slow" plaque formers," Journal of Clinical Periodontology, vol. 23, no. 11, pp. 1025-1031, 1996.

[9] S. A. Syed and W. J. Loesche, "Bacteriology of human experimental gingivitis: effect of plaque and gingivitis score," Infection and Immunity, vol. 21, no. 3, pp. 830-839, 1978.

[10] C. G. Daly and J. E. Highfield, "Effect of localized experimental gingivitis on early supragingival plaque accumulation," Journal of Clinical Periodontology, vol. 23, no. 3, pp. 160-164, 1996.

[11] M. A. Lie, M. M. Danser, G. A. van der Weijden, M. F. Timmerman, J. de Graaff, and U. van der Velden, "Oral microbiota in subjects with a weak or strong response in experimental gingivitis," Journal of Clinical Periodontology, vol. 22, no. 8, pp. 642-647, 1995.

[12] H. Loe, E. Theilade, and S. B. Jensen, "Experimental gingivitis in man," Journal of Periodontology, vol. 36, no. 3, pp. 177-187, 1965.

[13] J. Pratten, P. Barnett, and M. Wilson, "Composition and susceptibility to chlorhexidine of multispecies biofilms of oral bacteria," Applied and Environmental Microbiology, vol. 64, no. 9, pp. 3515-3519, 1998.

[14] F. Dalwai, D. A. Spratt, and J. Pratten, "Modeling shifts in microbial populations associated with health or disease," Applied and Environmental Microbiology, vol. 72, no. 5, pp. 3678-3684, 2006.

[15] H. Mihira, C. Sabota, and A. Warren, "Marketing shiitake mushrooms for their health benefits," Hortscience, vol. 31, no. 4, p. 651, 1996.

[16] S. Chun, E. Chambers, and D. Chambers, "Perception of pork patties with shiitake (Lentinus edode P.) mushroom powder and sodium tripolyphosphate as measured by Korean and United States consumers," Journal of Sensory Studies, vol. 20, no. 2, pp. 156-166, 2005. 
[17] R. Hearst, D. Nelson, G. McCollum et al., "An examination of antibacterial and antifungal properties of constituents of Shiitake (Lentinula edodes) and Oyster (Pleurotus ostreatus) mushrooms," Complementary Therapies in Clinical Practice, vol. 15, no. 1, pp. 5-7, 2009.

[18] U. R. Kuppusamy, Y. L. Chong, A. A. Mahmood, M. Indran, N. Abdullah, and S. Vikineswary, "Lentinula edodes (shiitake) mushroom extract protects against hydrogen peroxide induced cytotoxicty in peripheral blood mononuclear cells," Indian Journal of Biochemistry and Biophysics, vol. 46, no. 2, pp. 161-165, 2009.

[19] J. Regula and A. Gramza-Michalowska, "New cereal food products with dried shiitake mushroom (Lentinula edodes) added as a source of selected nutrients," Italian Journal of Food Science, vol. 22, no. 3, pp. 292-297, 2010.

[20] J. Reguła, "Nutritive value and organoleptic properties of cookies with the addition of dried shiitake mushroom (Lentinula edodes)," Zywnosc-Nauka Technologia Jakosc, vol. 16, no. 4, pp. 79-85, 2009.

[21] K. Boutaga, P. H. M. Savelkoul, E. G. Winkel, and A. J. van Winkelhoff, "Comparison of subgingival bacterial sampling with oral lavage for detection and quantification of periodontal pathogens by real-time polymerase chain reaction," Journal of Periodontology, vol. 78, no. 1, pp. 79-86, 2007.

[22] R. R. Price, H. B. Viscount, M. C. Stanley, and K. P. Leung, "Targeted profiling of oral bacteria in human saliva and in vitro biofilms with quantitative real-time PCR," Biofouling, vol. 23, no. 3, pp. 203-213, 2007.

[23] L. Ciric, J. Pratten, M. Wilson, and D. Spratt, "Development of a novel multi-triplex qPCR method for the assessment of bacterial community structure in oral populations," Environmental Microbiology Reports, vol. 2, no. 6, pp. 770-774, 2010.

[24] P. K. Sreenivasan and E. Gittins, "Effects of low dose chlorhexidine mouthrinses on oral bacteria and salivary microflora including those producing hydrogen sulfide," Oral Microbiology and Immunology, vol. 19, no. 5, pp. 309-313, 2004.

[25] J. Pratten, A. W. Smith, and M. Wilson, "Response of single species biofilms and microcosm dental plaques to pulsing with chlorhexidine," Journal of Antimicrobial Chemotherapy, vol. 42, no. 4, pp. 453-459, 1998.

[26] M. Wilson, "Use of constant depth film fermentor in studies of biofilms of oral bacteria," Methods in Enzymology, vol. 310, pp. 264-279, 1999.

[27] M. Daglia, A. Papetti, D. Mascherpa et al., "Vegetable food components with potentil activity on the development of microbial oral deseases," Journal of Biomedicine and Biotechnology. In press.

[28] R. I. Griffiths, A. S. Whiteley, A. G. O’Donnell, and M. J. Bailey, "Rapid method for coextraction of DNA and RNA from natural environments for analysis of ribosomal DNA- and rRNAbased microbial community composition," Applied and Environmental Microbiology, vol. 66, no. 12, pp. 5488-5491, 2000.

[29] R. G. Ledder, P. Gilbert, S. A. Huws et al., "Molecular analysis of the subgingival microbiota in health and disease," Applied and Environmental Microbiology, vol. 73, no. 2, pp. 516-523, 2007.

[30] P. S. Kumar, E. J. Leys, J. M. Bryk, F. J. Martinez, M. L. Moeschberger, and A. L. Griffen, "Changes in periodontal health status are associated with bacterial community shifts as assessed by quantitative $16 \mathrm{~S}$ cloning and sequencing," Journal of Clinical Microbiology, vol. 44, no. 10, pp. 3665-3673, 2006.

[31] P. D. Marsh, "Role of the oral microflora in health," Microbial Ecology in Health and Disease, vol. 12, no. 3, pp. 130-137, 2000.
[32] C. E. Kazor, P. M. Mitchell, A. M. Lee et al., "Diversity of bacterial populations on the tongue dorsa of patients with halitosis and healthy patients," Journal of Clinical Microbiology, vol. 41, no. 2, pp. 558-563, 2003.

[33] M. P. Riggio, A. Lennon, H. J. Rolph et al., "Molecular identification of bacteria on the tongue dorsum of subjects with and without halitosis," Oral Diseases, vol. 14, no. 3, pp. 251-258, 2008.

[34] B. J. F. Keijser, E. Zaura, S. M. Huse et al., "Pyrosequencinq analysis of the oral microflora of healthy adults," Journal of Dental Research, vol. 87, no. 11, pp. 1016-1020, 2008.

[35] J. Li, E. J. Helmerhorst, C. W. Leone et al., "Identification of early microbial colonizers in human dental biofilm," Journal of Applied Microbiology, vol. 97, no. 6, pp. 1311-1318, 2004.

[36] P. D. Marsh, "Are dental diseases examples of ecological catastrophes?” Microbiology, vol. 149, no. 2, pp. 279-294, 2003.

[37] J. Pratten, M. Wilson, and D. A. Spratt, "Characterization of in vitro oral bacterial biofilms by traditional and molecular methods," Oral Microbiology and Immunology, vol. 18, no. 1, pp. 45-49, 2003.

[38] E. Zaura, B. J. Keijser, S. M. Huse, and W. Crielaard, "Defining the healthy "core microbiome" of oral microbial communities," BMC Microbiology, vol. 9, article 259, 2009.

[39] H. F. Jenkinson and R. J. Lamont, "Oral microbial communities in sickness and in health," Trends in Microbiology, vol. 13, no. 12, pp. 589-595, 2005.

[40] N. Hatvani, "Antibacterial effect of the culture fluid of Lentinus edodes mycelium grown in submerged liquid culture," International Journal of Antimicrobial Agents, vol. 17, no. 1, pp. 71-74, 2001.

[41] M. Hirasawa, N. Shouji, T. Neta, K. Fukushima, and K. Takada, "Three kinds of antibacterial substances from Lentinus edodes (Berk.) Sing. (Shiitake, an edible mushroom)," International Journal of Antimicrobial Agents, vol. 11, no. 2, pp. 151-157, 1999. 

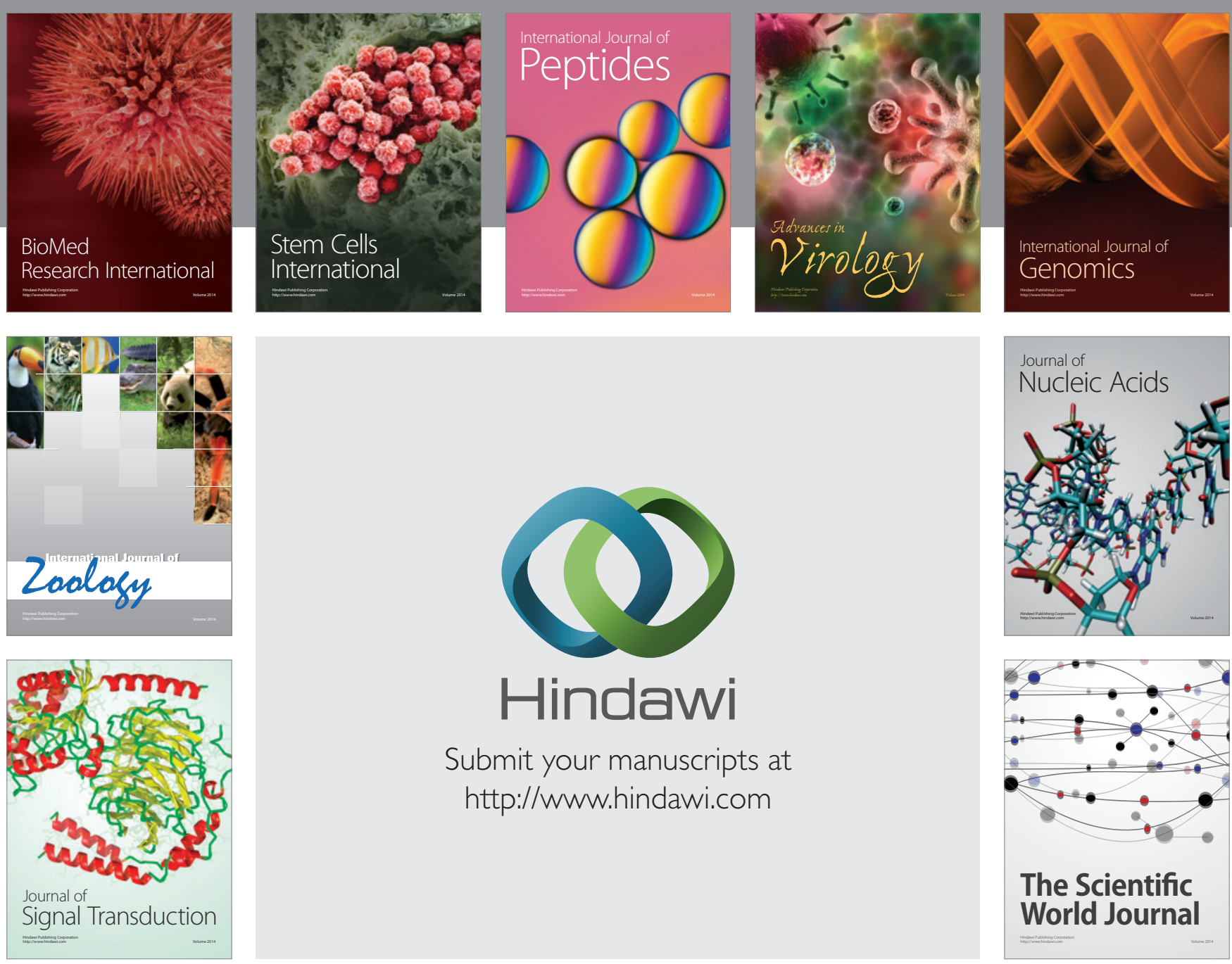

Submit your manuscripts at

http://www.hindawi.com
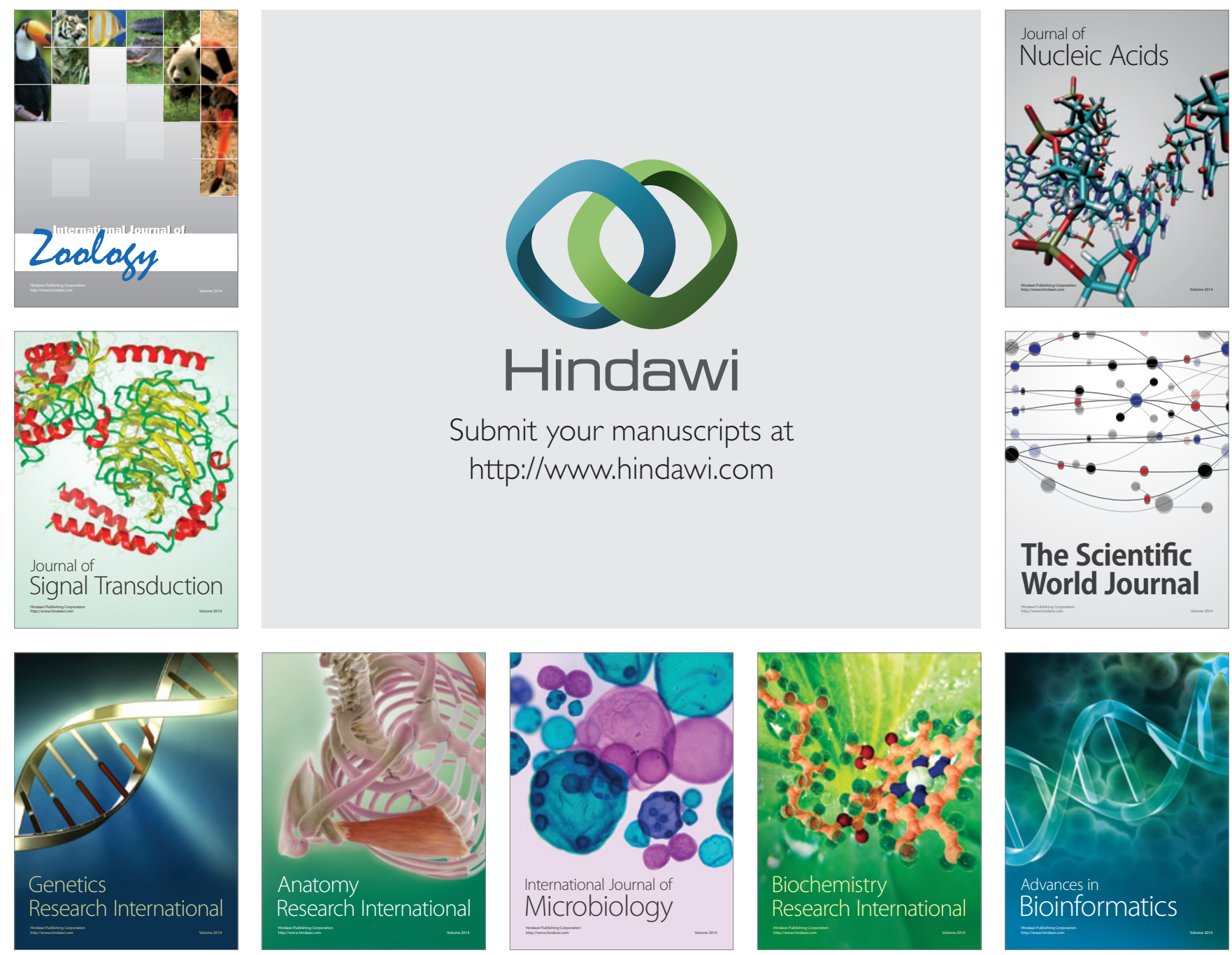

The Scientific World Journal
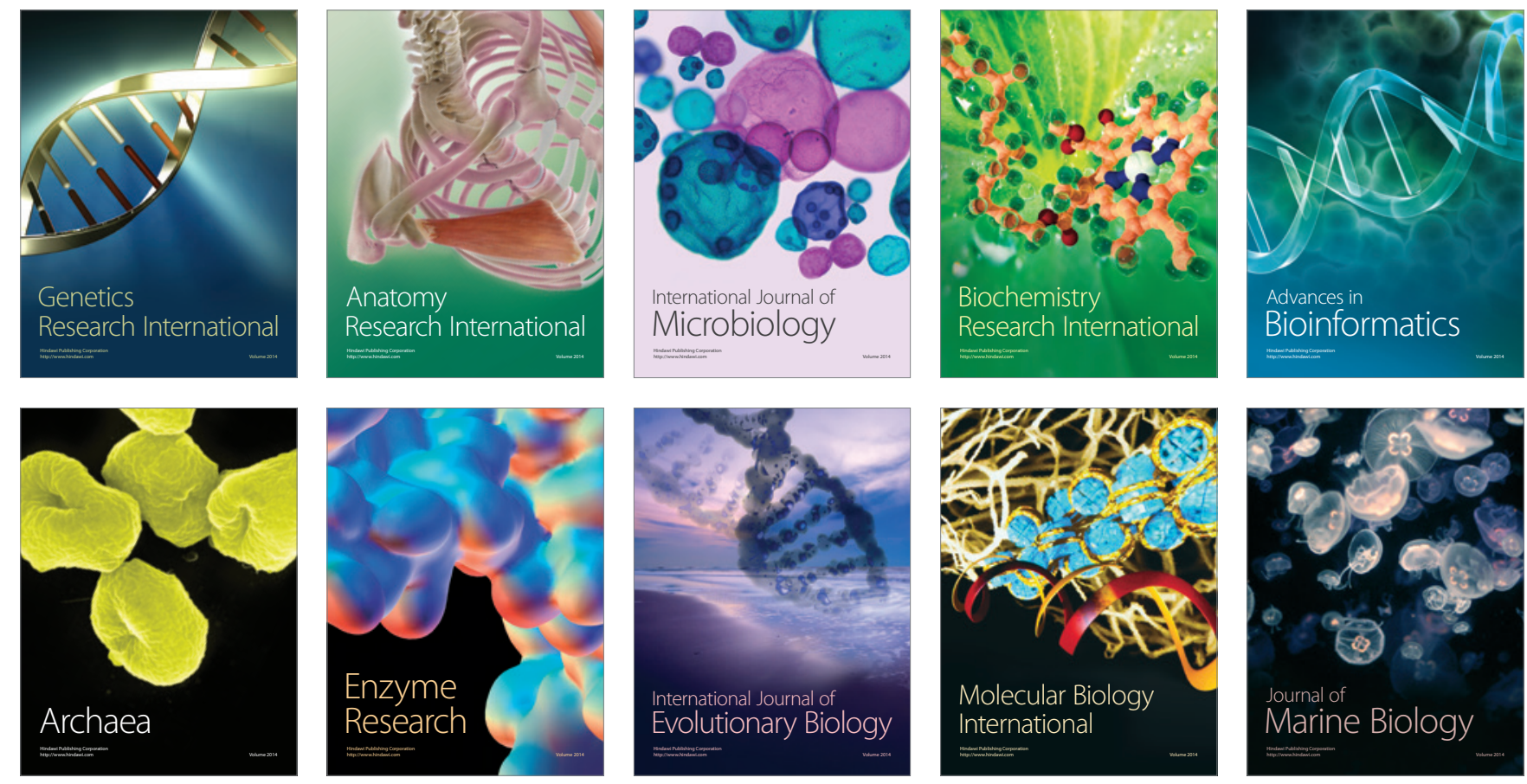